\title{
JULIÁN MEZA: EN \\ BUSCA DE LA PÁGINA PERFECTA \\ Armando Pereira*
}

- Tu historia intelectual ha sido muy intensa. Has incursionado en varios géneros: el ensayo, la novela, el cuento; pero has dejado grandes espacios entre un libro y otro. Me gustaría comenzar esta charla hablando de esa novela que escribiste hace más de 20 años: El libro del desamor. ¿Qué podrías decirnos de ella?

- Un par de cosas. La novela es muy desafortunada. Es una mala novela, aunque algo tiene. Su historia editorial es muy curiosa. Cuando terminé el borrador, se lo dí a un amigo poeta, quien a su vez se lo dio, sin decirme nada, a un editor; éste decidió editarlo, porque le pareció que estaba bien.

- ¿Quién era el editor?

- Emmanuel Carballo, que en aquellos días (1966) era uno de los prebostes culturales de México y reinaba en los pocos suplementos que había entonces. En uno en particular: el de la revista Siempre! Hizo ahí la primera crítica de mi novela. En ésta decía, casi literalmente: “¿Cómo es posible que Julián Meza se atreva a publicar esta novela?” Obviamente su reacción y la de algunos otros críticos, que también la apalearon, éstos sí con razón, porque señalaron lo que estaba mal en ella, me convenció de que tenía que pasar algún tiempo antes que pudiera escribir otra novela. No sé qué opinión tienes de El libro del desamor, pero hay una secuencia (son unos diez pequeños capítulos; desde entonces tenía

\footnotetext{
* Centro de Estudios Literarios, Instituto de Investigaciones Filológicas, UNAM.
} 
ARMANDO PEREIRA

la costumbre de escribir pequeños capítulos) sobre niños y pericos, que a mí me sigue gustando. La experiencia fue, en términos generales, mala, pero me enseñó que todavía no conocía bien mi idioma, que tenía que meterme en un proceso de aprendizaje, y así lo hice.

- A diferencia tuya, a mí me pareció bien esa novela. La leí a principios de los 70. Me impresionó el manejo que tenías del lenguaje, de la sintaxis. No encontré en ella a un principiante, sino a un escritor hecho, a un escritor en posesión de un lenguaje. Pero lo que me llama la atención no me lo formulé en ese entonces, me lo formulo ahora: ¿cuál era tu proyecto literario?

- Creo que es un intento de acercamiento a la literatura, pero a la vez se trata de una novela que refleja la situación que vivíamos los jóvenes en ese momento. La novela prefigura tanto el ambiente festivo, como el ambiente enloquecido que prevaleció poco después, en 68.

- Me asombra que hables del 68 como algo festivo. Creo que para mí y para mi generación, que es la que te sigue, 68 fue una tragedia. ¿Cómo ligas esta historia de fiesta y tragedia que es tu novela con lo que fue 68 ?

- Como en mi novela, el final del 68 fue trágico, pero empezó como una fiesta. Fue una fiesta porque posibilitó una liberación de deseos, instintos, pasiones tradicionalmente inhibidos, reprimidos, y el descubrimiento de que este país marginado de la democracia tal vez podía inscribirse en el futuro de la democracia. 68 tiene su parte horrorosa, pero no se debe olvidar la parte festiva. Me parece que tiene las características de todas las grandes fiestas sociales, en las que se da cita la polis, y aunque muchas veces acaban trágicamente, no pierden su dimensión lúdica.

- Recuerdo haber leído algo sobre el papel de los intelectuales franceses durante la Comuna de París. En especial, el de Flaubert. Fue algo que comenzó de manera casi solemne y terminó de manera cómica. Decidió leer un texto a los comuneros, pero antes de que terminara fue abucheado y expulsado del mítin con huevos y tomates. Al salir, dijo que no comprendía la Comuna. ¿Qué pasó con el intelectual mexicano en el 68? De alguna manera tú participaste en esto como intelectual, como militante universitario y creo que tienes algo que decir al respecto. 
- No, yo nunca fui intelectual ni militante. En 68 observé el acontecimiento con escepticismo. Dudaba de las posibilidades de la democracia política en México. Todavía dudo. Mi escepticismo se volvió desmesurado al final. Entonces fui presa de la rabia y la impotencia. A propósito de los intelectuales hay diferentes posturas. Flaubert no era un escritor preocupado por la política, sino un hombre exclusivamente dedicado a las letras, y cuando se produjo la Comuna de París era un novelista hecho. Se ha discutido mucho si Rimbaud estuvo o no en París en el momento de la Comuna. No importa. Lo importante es que él tiene poemas inspirados en la realidad, pero ligados a preocupaciones que van más allá de ésta. ¿Cuál es la diferencia entre Flaubert y Rimbaud? La edad. A diferencia de Flaubert, Rimbaud es un poeta muy joven en el momento en que se produce la Comuna de París y le interesa todo lo que ocurre más allá de la madre y de la casa. A Flaubert, al contrario, le interesan, y mucho, la madre, la casa y el loro convertidos en poesía con su prosa. En el caso de México, las cosas son un tanto distintas.

Hubo intelectuales comprometidos -algunos fueron a parar a la cárcel, como Revueltas-, porque participaron o estuvieron de acuerdo con el carácter democrático o socializante del movimiento, y estuvo bien que esos intelectuales se hubieran ligado a él; pero también lo hicieron porque ellos mismos necesitaban un espacio menos intolerante y más propicio a su actividad. ¿Qué es lo que otros intelectuales critican del 68? Es obvio, su aspecto enloquecidamente socializante, y me parece que esta crítica está bien en la medida en que esas aspiraciones carecían de porvenir. Hay datos muy curiosos. Se dijo entonces una cosa increíble: que el inspirador del movimiento había sido Marcuse. Yo dudo mucho que el uno por ciento de sus participantes lo hubiera leído.

- Yo era apenas un adolescente en 68 y creo que Marcuse marcó mi proyecto intelectual.

- Sí, pero se leyó después. El hombre unidimensional, publicado por Mortiz, era incomprensible. Y si después tratamos de leerlo, lo hicimos sin éxito: nunca lo entendimos. Algunos amigos han confesado que, como se les había dicho tanto que Marcuse era el inspirador del movimiento, decidieron leerlo, pero no entendieron nada. 
- Hay una parte de tu historia que me llama la atención: tus vínculos con Cuba. Sé que por esos años viajaste a Cuba y tuviste una revolución íntima con su Revolución. ¿Qué pasó?

- Mi acercamiento a la Revolución cubana fue porque me sugería cosas que no había observado en revoluciones anteriores (desde afuera, obviamente, porque nunca había estado en un país en donde hubiera habido una revolución), porque me decía cosas completamente distintas a las que sabía del socialismo, y fui a Cuba con curiosidad y entusiasmo. Cuando estuve ahí, justo después de haber publicado El libro del desamor, quedé sorprendido por dos razones. Una: la alegría, que ingenuamente ponía en relación con el carácter socialista del régimen, pero que no tenía nada que ver con él, sino con el espíritu festivo de los cubanos; y otra, que recuerdo claramente y subrayo: el ambiente de libertad que se respiraba en ese momento. Fui en 66 y en 67 , y prevalecía entonces un ambiente de tanta libertad que permitía que en una revista editada por amigos cubanos, Pensamiento Crítico, se publicaran artículos de Trotski, de gente opuesta a la ortodoxia soviética. Me sorprendí más espectacularmente la segunda vez, cuando se dieron cita en La Habana intelectuales de todo el mundo que sostenían las posiciones políticas más diversas, pero que al mismo tiempo tenían un elemento en común:

254 el antisovietismo. Y digo esto porque coincidía con mi punto de vista. Siempre fui antisoviético, y eso que aún desconocía los hechos terribles de los que me enteré más tarde. Lo festivo y la libertad que respire ahí, fueron para mí los atractivos de esa Revolución. Pero al final de mi segundo viaje a Cuba, en febrero de 1968, ocurrió algo inesperado: un proceso a un viejo estalinista, Aníbal Escalante. No me llamó la atención el proceso en sí, sino la manera como se efectuó, pues se trató de un proceso estalinista que me empezó a distanciar de Cuba. Pero lo que me separó definitivamente de ese régimen fue la nota aparecida en Granma, a raíz del 2 de octubre de 1968, en la que el gobierno cubano adoptó una actitud aún más miserable que la de los periódicos mexicanos, pues dio cuenta de esa fecha diciendo que en la Plaza de las Tres Culturas habían muerto unas cuantas personas. No recuerdo bien si decía 3 o 24. El hecho en sí es indignante, pero lo es más porque pretendió anular el proceso de democratización que se inició entonces. 
- ¿Crees que la posible apertura democrática que se puede estar viviendo hoy en México parte del 68 ?

- Definitivamente sí. Antes del 68, México era muy distinto del país en el que vivimos ahora. Me refiero en particular a lo que llamo el espacio de la libertad, entonces prácticamente inexistente. A raíz del 68 se generan espacios de libertad que este país no conocía, y no sólo en el aspecto de la libertad de expresión, intelectual, cultural, artística. Para mí, el 68 representa el despertar de los sentidos, del placer, de comportamientos en gran medida inéditos. Antes del 68, México era un país pudibundo, mojigato. Y no es que ahora la pudibundez haya desaparecido, pero quizá es menos ñoña. Además, junto con la instauración de un lento proceso de democratización, se produce una apertura en la vida cotidiana. Antes del 68, el país vivía a la hora del siglo XVII; después empezó a vivir quizá no a la hora del siglo XX, pero se acerca.

- Has acentuado mucho la apertura de la vida cotidiana, la entrega al placer, la búsqueda del deseo. ¿Por qué después del 68 te vas a Europa?

- Me voy a Europa por una razón muy práctica: quiero hacer un posgrado, y elijo Francia porque desde niño hubo una tentación francesa en mí.

- ¿Qué pasa cuando llegas a Europa, quiénes son tus amigos?

- Aunque antes me hice amigo de muchas otras personas, mi primer y más grande amigo en Francia es André Glucksmann. Lo conocí antes de ir a Francia puesto que traduje para la Editorial ERA uno de sus primeros libros, Estrategia y Revolución en Francia, escrito al vapor de los acontecimientos del 68. Este fue el punto de partida de una relación que se ha enriquecido al paso de los años. Yo llegué a una Francia post-68, en donde la gente que había participado en este proceso empezaba a desertar. En esa época, Glucksmann aún era maoísta, pero poco a poco dejó de serlo, y esto fue muy importante porque, políticamente, me ayudó a cuestionarme y a cuestionar a las izquierdas que aún me parecían aceptables. Como te dije hace un rato, yo siempre había criticado el sovietismo y me había distanciado de los cubanos, pero ahora pasaba a una nueva fase, en la cual empezaba a cuestionar las cosas que 
ARMANDO PEREIRA

ocurrían en China. Glucksmann es mi primer contacto con este cuestionamiento, pero no el único. Tengo muchos amigos que también vivieron este proceso, y más adelante conocí a varios intelectuales franceses que para mí han sido determinantes: Castoriadis, Lefort, Foucault y, sobre todo, Paul Thorez, mi amigo, mi hermano.

- ¿Por qué te aventuraste a publicar un libro en ensayos como Cándidos y Tartufos?

- Cuando publiqué este libro (1989), pude parecer extemporáneo, pues un objeto de su crítica, el totalitarismo, se extinguía. Sin embargo, fue importante publicarlo por dos razones. En primer lugar, porque expresa mi ejercicio de la crítica en una época en la que resultaba inaceptable para los dinosaurios marxistas, y queda como constancia. Y en segundo lugar, porque mucho de lo que ahí critico aún se manifiesta en México, y en otras partes: el intelectual cortesano, el ideólogo oportunista, el clérigo fanático, el escritor lacayo deseoso de poder... La servidumbre voluntaria, vaya.

- Esa forma de sentirse a gusto en Francia ha levantado una especie de rumor en México, que me parece que no sólo comparten tus enemigos, sino también tus amigos. Quisiera hacer una especie de parangón. A principios de siglo la crítica periodística chilena hablaba de Huidobro como un poeta francés nacido en Chile. Hay gente en México que hace una broma: dice que tú eres un pensador francés nacido en Orizaba. ¿Qué piensas de esto?

- Para mí es muy elogioso que me compares con Huidobro, pues es uno de los más geniales poetas latinoamericanos del siglo XX, ciertamente afrancesado, y qué bueno. En algún momento la gente pensó que me insultaba al cambiarme el nombre y apellido y decirme Julién Mezá. Recuerdo una polémica que tuve con Héctor Aguilar Camín en unomásuno, en donde Héctor dirigía sus cartas a Julién Mezá. Para mí fue muy divertido. Yo le respondí llamándole Héctor von Ilhuicamina, porque con su actitud Héctor quería decirme que él era más mexicano que yo, porque yo era afrancesado y él, en cambio, era muy mexicano, y por lo tanto, pensé yo, muy Ilhuicamina, pero además, como era marxista, también tenía su lado extranjerizante y de ahí eso de von. Esto me divier- 
te por una sencilla razón: tengo una debilidad enorme por Francia que no me hace sentirme mal, ni me hace pensar que soy menos mexicano que otros; al contrario, creo que conozco mi idioma mejor que muchos mexicanos que pretenden ser escritores. Además, en Francia no sólo conocí a estos amigos de los que te he hablado, sino que viví en un mundo que se volvió muy importante para mí en otros aspectos, pues es un país cuya cotidianidad me agrada, en donde hice grandes amistades con gente sencilla a la que nuestros vanidosos turistas considera pedante, grosera, xenófoba. Es el único país que conozco con una cocina y una bebida de primera. Cuando me introduje en las letras francesas, el amor que le tenía a la literatura desde antes de escribir mi primera novela creció. Conocí a mis contemporáneos franceses y me familiaricé con los grandes escritores franceses del pasado. Fue una época en la que pude leer tranquilamente a Rabelais, a Stendhal, a Flaubert, a los grandes poetas parnasianos. Descubrí a Mallarmé, a Apollinaire, accedí a un mundo poético y literario que conocía poco.

- Julién Mezá, entiendo esta afición por Francia que comienza por un buen vino, una buena comida y termina con Rimbaud o Mallarmé. ¿Tu vinculación con la revista Vuelta proviene de ahí también?

- Curiosamente sí. Conocí a Octavio Paz gracias a André Glucksmann. No me lo presentó un mexicano, sino un francés. Cuando él vino al espectáculo de los nuevos filósofos en México, exigió que yo fuera su traductor. Así, en la primera reunión que hubo en Televisa, Glucksmann me presentó a Octavio Paz, y desde entonces tuve el privilegio, el gusto, el placer de ser su amigo. En una época en la que yo era un apestado político en México, Paz me acogió con una bondad sin límites.

- A lo largo de 15 años de colaboración con Vuelta, ¿cómo te sentiste en esa revista?

- Me sentí siempre muy bien tratado, no sólo por Octavio, sino por la gente que colaboró con Vuelta, que hizo Vuelta, en donde tuve grandes amigos; pero hay algo que quiero destacar: yo fui en Vuelta una especie de escritor marginal: me ocupé de autores, libros y temas que hoy son fundamentales en la literatura europea, pero aquí parecían no existir, tal vez porque alguna vez se creyó que la literatura 
ARMANDO PEREIRA

se había desplazado hacia la periferia de Occidente y que en Europa occidental no quedaba nada. Escribir acerca de autores como Roberto Calasso era, en México, una excentricidad, una aventura. Soy un aventurero que estuvo en Vuelta sin ser de Vuelta.

- Me llama la atención lo de marginal. En un sentido lo entiendo. Marginal con respecto al comunitarismo internacional está bien, pero por qué marginal con respecto a Vuelta. ¿Qué representó Vuelta en la cultura mexicana, en la cual te tienes que sentir marginal o te presentas como marginal?

- En la cultura mexicana contemporánea Vuelta desempeñó un papel capital. No sólo nos puso en relación con los grandes escritores europeos que otras publicaciones quisieron dar la impresión de descubrir, como Kundera, por ejemplo, sino que definitivamente se preocupó con pasión por la democratización de México, cuando las izquierdas estaban hipotecadas al sovietismo. Yo participé en este proyecto, pero ahora mis intereses son otros, sobre todo desde el punto de vista literario: me ocupo de los grandes escritores europeos de hoy, que aquí se desconocen o se desprecian, en beneficio de autores locales muy menores.

- En esa misma línea has desarrollado una labor importante en revistas como Estudios, publicada por el ITAM, o en la revista de la Universidad de México. ¿Qué nos puedes decir de la revista Estudios que diriges?

- La revista no fue idea mía, sino del entonces mi jefe, mi amigo, Rodolfo Vázquez, y me parece que fue una buena idea. En esta revista hemos publicado contribuciones interesantes, importantes. Es verdad que no todo lo que se publica en Estudios es aceptable. Se publican textos que no tienen mucho valor, como en todas las revistas, como en todos los suplementos culturales, pero en condiciones muy peculiares: se trata de textos que reflejan maneras de pensar o ideas que no me interesan o con las cuales estoy en descuerdo, pero jamás me atrevería a prohibirlos. Creo que Estudios es una revista académica plural. A mí me parece muy sano que en el medio académico, en general tendencioso, ideológico, profiláctico, se puedan publicar revistas con opiniones diversas. 
- Publicaste tu segunda novela, La huella del conejo. La crítica que he podido leer sobre ella la destaca sobre todo por ser una parodia del descubrimiento de América. El recuerdo que tengo de la lectura que hice del original, y del libro una vez publicado, es la de una parodia sobre el hallazgo de dos culturas, el descubrimiento de América. Creo que tu intención va más allá y que hay una propuesta sobre el lenguaje. Tu novela es fundamentalmente un trabajo sobre el lenguaje literario. ¿Cómo definirías La huella del conejo?

- Empiezo por lo último: no puedo ni me interesa definirla, pero creer que hice una sátira brutal o despiadada del descubrimiento de América me parece una mala lectura de la novela. El descubrimiento de América es, literalmente, un pre-texto que se me ocurrió como punto de partida para escribir un libro en el que no se descubre nada, excepto -y tienes razón en esto- el lenguaje. La tarea fundamental en esta novela consistió en pelearme con las palabras. Fue la apuesta y el resultado acompaña al viaje que hay en una novela, pero que no tiene nada que ver con el descubrimiento de América.

- Ahora que hablas de la apuesta del lenguaje, yo diría que hay parodia de la novela y parodia del lenguaje. Pienso, sobre todo, en el estilo barroco, en algunos escritores latinoamericanos, en cuya obra hay, al mismo tiempo, también un trabajo con la parte gozosa del lenguaje. Se trata un poco de jugar con las palabras, con la parte lúdica del idioma, y también de una erotización de las palabras que utilizas en la novela. ¿Cómo funciona esto?

- Efectivamente, creo que la parodia fundamental es la del lenguaje, que algunos que han criticado la novela no han entendido. Recuerdo la reseña de un amigo que dice que está muy mal que haya yo escrito la novela en un estilo del siglo XVI. Creo que no la leyó, y al azar la abrió en alguna página en donde parodio ciertas expresiones del siglo XVI. En la presentación que hiciste de la novela decías, junto con alguien más, que se trata de una novela con una estructura que recuerda a ciertos autores barrocos, y efectivamente los recuerda, pero la intención no es homenajearlos, sino parodiarlos; el barroco no es mi género preferido, y justamente la mejor actitud que he podido adoptar frente al mismo 
es la parodia. Por otro lado, está el goce de la escritura que apunta, obviamente, al goce de la lectura. Es la intención fundamental: comunicar el enorme placer de escribir a la lectura de la novela. Se trata de dar a la escritura en prosa la dimensión que puede tener cuando se hace poesía. Pretendo acercar la prosa a la poesía.

- Hay algo en la novela que muchos lectores de corte tradicional extrañarán al leerla: la ausencia de una anécdota, de personajes definidos psicológicamente y, sobre todo, la acción, los sucesos, los acontecimientos. Cuando te digo que es una obra del lenguaje, es justamente porque me parece que más que crear un personaje o una situación, más que contar una anécdota, se trata del juego, del trabajo con las palabras. En este sentido se podría ver también a tu novela desde una perspectiva totalmente moderna, desde la narrativa de Joyce hasta hoy. Pero, ¿por qué esta ausencia de anécdotas, de personajes, que en muchos casos podría llevarnos a pensar que no es una novela, que es un texto inclasificable?

- Hay anécdota y no hay anécdota. No es la anécdota que yo llamo convencional, sino pequeñas anécdotas que eslabono mediante personajes que apenas se están definiendo cuando ya se murieron, o desaparecieron o se fueron, lo cual da una especie de concatenación, más que al personaje o a la anécdota, al lenguaje, y ése es el propósito. Sin embargo, también hay personajes, como la propia escritura. Quieren que les cuente algo, como se los cuenta José Agustín o Gustavo Sainz o cualquiera de éstos y no era mi intención. No quiero entretener a críticos haraganes, amas de casa y actrices de telenovelas tumbadas en la playa. Creo que es un libro que leerá poca gente, y así está bien. Cuando lo escribí, me reí mucho, y pensé en los pocos que se reirían con él. Una característica de esta escritura es que rompe con ciertas ideas convencionales acerca de la novela, según las cuales tiene que haber un personaje perfectamente definido psicológicamente, una descripción ambiental exhaustiva y un sinnúmero de diálogos inútiles. Yo creo que, cuando una novela aspira a ser tal, no debe parecerse a ninguna otra, sino proponer algo nuevo. Creo que vivimos un momento muy peculiar de la historia de la novela. Me parece que ésta se renueva vigorosamente en todo el mundo, que vive uno de sus grandes momentos, pero la gente se sorprende a 
menudo al leer ciertas obras que no le recuerdan los convencionalismos a los que está acostumbrada. Se lee El Danubio, de Magris, y se dice "no es una novela". Si Magris dice que lo es, yo estoy de acuerdo con él. ¿Por qué no lo sería? No es una novela si se la compara con otras de corte tradicional, pero por sí misma lo es, al igual que Las bodas de Cadmo y Harmonía, de Calasso y La casa de Pushkin, de Bítov. Todas ellas están escritas de una manera original e irrepetible y precisamente por eso son novelas. Son intentos por generar nuevas formas de escritura que vienen, a mi modo de ver, a revitalizar el género conocido como novela. Al hablar de personajes hay algo que me llama la atención en La huella del conejo: un personaje que aparece en pocos momentos, tres o cuatro, se oculta en el texto y creo que es uno de los leit motiv de tu novela: ese judío errante. Ahasverus, que aparece en momentos claves del texto. ¿Qué papel desempeña Ahasverus en la novela?

- Realmente el verdadero autor de la novela es Ahasverus. Él es quien la escribe mientras participa de los acontecimientos. Habla también de sí mismo, sólo que lo hace en tercera y no en primera persona. Es muy modesto, pero es uno de los protagonistas fundamentales y el único que puede contar una historia que dura 150 años. Matusalén la habría podido contar, pero no era escritor. Ahasverus es una especie de escritor silencioso, que apenas susurra. Todo lo que encierra este personaje es algo que no me propongo descubrir al lector. Si éste tiene curiosidad e indaga quién es Ahasverus, quizá puede saber más acerca de la personalidad del narrador. Entonces, el personaje más importante de la novela es aquel que en apariencia está más ausente. Ahasverus es mucho más importante que el Almirante, que es una anécdota, o que Carlos El Etíope, que es otra, y aun que Piccolomini, que a mí me parece es, de acuerdo con las convenciones de lo que se cree una novela, el personaje más definido, el que presenta más rasgos, el que actúa y vive una serie de aventuras.

- ¿Cuál sería el tema de tu novela, de qué trata?

- Es una aventura. No una aventura en la que las acciones suceden vertiginosamente manteniendo en vilo la atención del lector, sino una aventura literaria. 
- Yo creo que pones el acento en la factura de la novela, más que en el contenido. Esto me parece fundamental, sobre todo en el momento actual de la narrativa mexicana, en donde parece que este cuidado por el lenguaje se está perdiendo. ¿Cómo ubicarías tu novela dentro del panorama actual de la literatura mexicana?

- Como algo totalmente ajeno.

- Te pregunto esto porque hace un momento has hablado de tu marginalidad, a propósito de Vuelta, pero también a propósito de la cultura mexicana. En alguna medida siento que tu novela es un poco marginal frente a lo que se está escribiendo hoy en México.

- Definitivamente lo es. He hojeado algunas novelas recientes y veo que a sus autores les interesan sobre todo las anécdotas mal contadas. Uno escribe de sus traumas infantiles o de su provincia, el otro de la abuela, el chocolate, los ojos, el golfo, las pérdidas. A mi esas cosas no me interesan, pero por la manera como están escritas. Lo que más me llama la atención, no es que se entretengan con asuntos triviales (la gran literatura está hecha de estos asuntos) sino lo mal que escriben. Flaubert decía que el tema de Madame Bovary es trivial. Y es cierto, no puede haber un tema más ordinario en la literatura que el adulterio. Lo importante en Flaubert es cómo cuenta, cómo narra tal adulterio. Tengo la impresión de que actualmente se escribe de cualquier manera. Hay una especie de grafomanía, de la cual hablo en mi novela. Hoy cualquier cortesano, cualquier lacayo escribe una novela. Peor aún: cuando una fulana es incapaz de poner dos palabras juntas, alquila un corrector de estilo. Yo creo que la gran apuesta de la literatura es la escritura, no las anécdotas, que son pretextos para hacer literatura, y están fuera de este país.

- ¿Con quién emparentarías esta novela?

- Por el amor a la lengua, con Borges, que, al igual que Flaubert, aspiraba a escribir la página perfecta, y al igual que Borges escribió muchas páginas perfectas. Yo me conformaría con escribir algún día una sola página perfecta.

- Acabas de terminar una tercera novela, El arca de Pandora. ¿Qué podrías decirnos de ella? 
- En El arca de Pandora hay más personajes en el sentido convencional, hay más acción, hay anécdotas; pero lo que trato de probar en esta novela es que, aun si se toman en cuenta personajes, anécdota, etcétera, es posible prestarle atención sobre todo a la escritura. No soy yo el que cuenta la anécdota; es la escritura la que la va haciendo. Una vez más, lo esencial ha sido tratar de subordinar la anécdota a la escritura. Hay exigencias del mercado, de la moda: abordar ciertos temas, hacer política, psicología, erotismo, etcétera. Esto no me interesa. Me interesa penetrar en ciertos aspectos del mundo para poner de relieve la escritura. No creo que la anécdota sea fundamental; lo importante es la escritura. No quiero entretener a como dé lugar. Lo importante de la historia es la manera cómo está escrita. La apuesta sigue siendo la misma, aunque se trate de una novela en muchos aspectos diferente a la anterior.

- Al comenzar esta charla, aludí al tiempo que dejabas transcurrir entre un libro y otro. Lo extraño ahora es que, en un lapso tan breve, hayas terminado tres novelas. Para concluir, quiero preguntarte: ¿qué pasó?

- Cuando me preguntaste por qué, después de haber publicado el Libro del desamor, dejé de escribir tantos años, yo te respondí que me di cuenta de que necesitaba aprender a escribir y me puse a tratar de hacerlo. Creo que he encontrado una veta y no pienso desaprovechar el momento, la oportunidad de seguir explorándola, hasta lograr eso que Flaubert, primero, y Borges, después, llamaban la página perfecta. 
La reproducción total o parcial de este artículo se podrá hacer si el ITAM otorga la autorización previamente por escrito. 